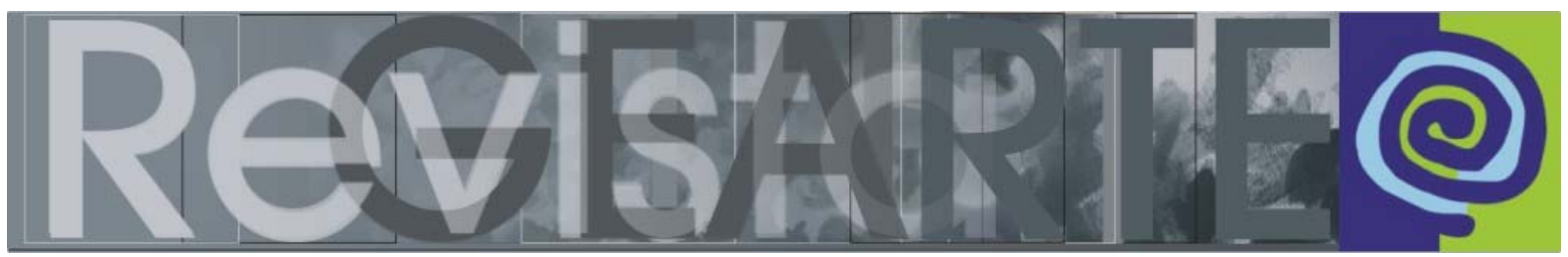

ISSN 2357-9854

\title{
Movimento autopromocional no âmbito da televisão no país
}

\author{
Maria Lília Dias de Castro (UFSM - Brasil)
}

\begin{abstract}
RESUMO
A proposta deste trabalho, na esteira da discussão entre promocionalidade e autopromocionalidade, volta-se especificamente para o exame dos procedimentos e das estratégias empregadas pela Rede Globo de Televisão, por ocasião do lançamento de uma de suas produções ficcionais: a telenovela Joia Rara (da faixa horária das 18 horas), para verificar, nos planos paratextual, referente ao entorno socioeconômico, político e cultural de atuação da empresa, e intertextual, referente às relações contraídas com outros textos da grade, a forma como a emissora propõe o contrato comunicativo com seu público e desenvolve ações autopromocionais de divulgação desse novo produto.
\end{abstract}

PALAVRAS-CHAVE

Promocionalidade e autopromocionalidade. Estratégias. Planos paratextual e intertextual. Produção ficcional.

\section{ABSTRACT}

The purpose in this paper, regarding the discussion between promotion and self-promotion, turns specifically to the examination of procedures and strategies applied by the Globo Television Network, at the launch of one of his fictional productions: the soap opera Joia Rara (the schedule of 18 hours) to check, in paratextual plans, referring to the socioeconomic, political and cultural environment in which the company operates, and intertextual, referring to contracted relationships with other texts of the grid, the way the station proposes the communicative contract with your audience and develops self-promotional actions to disclosure this new product.

KEYWORDS

Promotion and self-promotion. Strategies. Paratextual and intertextual plans. Fictional production.

\section{Observações introdutórias}

Como todos sabem, ninguém fala dos outros sem, antes, falar de si próprio. E o mesmo parece acontecer com a televisão, quando está no ar: tudo o que nela é produzido e exibido tem, no fundo, a crescente vocação de falar muito mais de si do que dos acontecimentos do mundo exterior. Esse movimento caracteriza aquilo que Eco denomina de neotevê, pois é uma televisão que, cada vez mais, fala sempre menos do mundo exterior. "Ela fala de si mesma e do contato que estabelece com o próprio público" (ECO, 1984, p. 182), concretizando-se sob criativas formas de manifestação. 
Ora, essa tendência parece comprovar, também, o reconhecimento de uma propriedade comum, ou papel primordial, que, no interior da televisão, praticamente subsume as tradicionais funções de informação, entretenimento, educação: trata-se da função promocional. Por promocional entende-se todo o movimento realizado para divulgar e/ou projetar algo, seja aquilo que se refere a anunciantes que compram espaço para exibir seus produtos e, nessa medida, fortalecem o caráter comercial da emissora (produção promocional); seja aquilo que se refere à própria televisão quando se propõe a mostrar o próprio fazer, imprimindo caráter autorreferencial ao que exibe (produção autopromocional). Até se pode dizer que, no âmbito da televisão, a promoção não apenas permeia tudo o que é feito nessa mídia, como se constitui em um princípio comum e abrangente que se atualiza mediante o emprego de diferentes estratégias que se manifestam em distintas e específicas configurações.

Sendo assim, os produtos de natureza promocional e autopromocional precisam ser examinados como textos, os quais, articulados em um universo próprio, industrialmente construído, configuram-se como produtos oferecidos ao mercado. Aliás, os textos são o objeto de estudo por excelência da semiótica discursiva, ponto de partida para uma análise das articulações que levam à compreensão da significação e dos sentidos da produção midiática.

Nessa perspectiva, a proposta deste trabalho é examinar as diferentes estratégias utilizadas em produções autopromocionais, veiculadas pela Rede Globo de Televisão (RGT), levando em conta, de início, a posição da empresa no contexto de atuação e a abrangência da situação comunicativa proposta por ocasião do lançamento de um novo produto ficcional, no caso a telenovela Joia Rara; e, na sequência, os impactos que essa oferta trouxe à grade de programação, considerando reiterações e/ou apropriações de outras vozes, no período específico de pré e pós-lançamento, o que corresponde às duas semanas, anterior e posterior, à estreia (9 a 23/09/2013).

No desenvolvimento do raciocínio, busca-se indicar, mesmo que de forma breve, a base teórica de sustentação do trabalho, articulando o conceito de 
interação social de Bakhtin (para dar conta da abrangência da situação comunicativa), com o de estrutura narrativa de Greimas (para investigar o texto).

\section{Fundamentos teóricos da investigação}

O crescimento avassalador dos meios de comunicação trouxe, como consequência para o mundo moderno, a formação de grandes conglomerados midiáticos, hoje responsáveis pela veiculação controlada das informações e dos saberes, o que thes garante uma concentração exagerada de responsabilidade e de poder. No Brasil, o mesmo fenômeno se repete através das grandes organizações midiáticas, as quais se veem divididas entre, de um lado, a manutenção de uma estrutura mercadológica que dê amparo àquele negócio (papel de empresa privada); e, de outro, a oferta de informação, educação, entretenimento ao público telespectador que pretende fidelizar (papel de emissora de comunicação). A dupla condição transforma os lares brasileiros em espaço de excelência para a exposição das realizações dessas empresas, com incentivo às novas práticas e hábitos culturais, com vistas à valorização da audiência e à consequente atração dos anunciantes aos espaços disponibilizados.

Isso significa dizer que o paradigma dominante da televisão brasileira é a sustentabilidade financeira, o que a torna uma indústria que, mesmo sendo de natureza cultural, também está submetida às leis do mercado, e esse parece ser seu principal valor de base. Nesse sentido, dominada pelo interesse econômico, a televisão mais e mais se encontra condicionada por "uma regra elementar, em que a demanda regula a oferta e o conhecimento dos gostos do público acaba se tornando a única condição levada em conta pela produção" (WOLTON, 2006, p. 34).

Nesse cenário, o processo de interação instaurado pela emissora diz respeito ao seu contexto de atuação, envolvendo panorama de fundo, comando diretivo da empresa, participação em ações sociais propostas à comunidade, capacidade tecnológica, diversidade de novas ofertas, investimento pesado na própria produção, e tudo isso pensando na construção de um perfil qualificado, capaz de lhe render as garantias necessárias à manutenção da empresa. 
Sendo assim, uma proposição teórica capaz de dar conta das produções televisuais requer a articulação entre o olhar amplo da situação e a pontualidade do texto, o que significa, no âmbito desta investigação, recuperar a noção de evento social de interação, trazida por Bakhtin; e a de narratividade e de percurso gerativo de sentido, lançados por Greimas.

Bakhtin entende a linguagem como processo (atividade), e não como sistema, o que implica sua relação com a situação concreta, com a vida prática, com o evento social que envolve os sujeitos, conferindo um caráter sociológico às leis que presidem essa atividade (BAKHTIN, 1981, p.127). O foco principal é o ato singular de comunicação humana, concretamente situado, em que o enunciado se particulariza como a unidade de comunicação em que ocorre a interação entre sujeitos; já a enunciação, pela natureza social e ideológica que encerra, corresponde ao produto da interação de dois sujeitos socialmente organizados, isto é, ela é vista como uma realidade de linguagem, como uma estrutura socioideológica, que só existe dentro de um contexto, deixando clara a correlação estreita entre o enunciado e a situação concreta de sua enunciação.

De maneira geral, o autor russo entende a comunicação não como um sistema acabado, mas um contínuo processo de vir a ser, uma atividade, compreendendo assim o evento singular que se materializa no enunciado, o ato realizado entre sujeitos (relação eu/outro) e o caráter axiológico (dimensão valorativa).

Além disso, Bakhtin entende que essa materialização do enunciado, ou texto, mantém relações com outros textos que o precedem e/ou sucedem na cadeia, visto que traz em si ecos, reverberações de outras produções. Os textos, assim, refletem e refratam o mundo: ao mesmo tempo em que se referem ao real, à materialidade do mundo, eles também propõem, sugerem interpretações, mostrando a possibilidade de várias verdades, concomitantes e/ou contraditórias, sobre aquilo que se diz. Daí porque, nesse nível, também se manifestam outras tantas vozes, inúmeras semânticas, apropriadas de outros textos (BAKHTIN, 1997). Esse processo de caráter dialógico implica tanto uma orientação para outros textos como a incorporação de ângulos distintos de visão 
que se entrecruzam no seu próprio interior. Nessa perspectiva, todo dizer orienta-se para o já-dito, é réplica; é direcionado para a resposta, pressupõe um receptor. Essa internalização do diálogo, da heterogeneidade faz dele a expressão e articulação de múltiplas vozes sociais.

As proposições defendidas por Bakhtin ajustam-se perfeitamente ao estudo da televisão e da promoção, na medida em que a análise dessa mídia exige que se leve em conta a situação concreta criada entre sujeitos socialmente organizados e o produto concreto (texto) da interlocução que entre eles se estabelece, além das relações que são estabelecidas com outros textos.

Relativamente à pontualidade textual, Greimas assume o desafio de perseguir o plano do conteúdo, centrado no conceito de narratividade, que possibilita ao analista verificar como aquele texto faz para dizer o que diz, e de explicar as relações lógicas instituídas a partir do texto, e responsáveis pela produção de seus efeitos de sentido (GREIMAS, 1979).

A narratividade é concebida como uma organização discursiva, disposta em níveis que constituem o percurso gerativo, o qual é reiterado a cada texto. Possuindo, cada um, uma gramática própria, esses níveis vão do mais abstrato e simples ao mais concreto e complexo, e estão assim constituídos: (1) fundamental - nível das relações mais profundas e abstratas do conteúdo, relativas aos valores e oposições semânticas, o qual reúne as condições mínimas de apreensão e/ou produção da significação; (2) narrativo - nível lógicosemântico em que os valores são antropomorfizados, isto é, passam a ser manifestados pelos sujeitos, através de sucessão de estados e de transformações; (3) discursivo - nível responsável pelo modo de contar as narrativas, pela colocação em discurso das estruturas narrativas, a partir da instância da enunciação que constitui o conjunto do percurso. Os dois primeiros níveis, ou estrutura semionarrativa, são responsáveis por reger a organização do discurso, anteriormente a sua manifestação; enquanto o último, ou discursivização, é o que diz respeito ao processo de produção do discurso, ou o todo de significação. 
No nível da discursividade, Greimas propõe o exame dos dispositivos que, articulados, são responsáveis pela significação: tematização (procedimento de conversão semântica dos valores da estrutura fundamental em temas de discurso), figurativização (instalação de figuras que afeta o conjunto das ações, os atores, o espaço, o tempo, e conferem sentidos ao discurso), actorialização (instituição de atores no discurso para reunião dos diferentes elementos dos componentes semântico e sintáxico), espacialização (procedimento de localização espacial, efetuados pelo enunciador para dar ao discurso uma organização espacial mais ou menos autônoma), temporalização (conjunto de procedimentos da ordem do tempo que segmenta e organiza as sucessões temporais).

Esse entendimento teórico, articulando o pensamento bakhtiniano com os fundamentos greimasianos, permite, assim, a projeção de uma construção teórico-metodológica capaz de reunir as seguintes instâncias: o exame das relações do texto com o entorno social, econômico, político e cultural em que a emissora centra sua atuação e com o contrato comunicativo que deseja firmar com o público (dimensão paratextual); o exame das relações do texto em análise com outros textos que o precedem e/ou sucedem na cadeia sintagmática ou com aqueles que Ihe servem de modelo, de paradigma (dimensão intertextual); o exame das relações contraídas pelo texto na perspectiva das articulações internas entre expressão e conteúdo (dimensão intratextual).

Dadas as limitações deste texto, a análise privilegia as estratégias relativas às decisões da emissora, dentro do entorno de seu desempenho, e ao contrato comunicativo/enunciativo que pretende firmar com o telespectador (dimensão paratextual); e aquelas relacionadas à utilização de outros produtos, espalhados na grade de programação, que ela seleciona como espaços adequados para essa difusão (dimensão intertextual). 


\section{Análise da autopromocionalidade em Joia Rara}

\subsection{Dimensão paratextual}

A paratextualidade diz respeito, de um lado, à relação da Rede Globo de Televisão (RGT), com seu entorno social, econômico, político e cultural e, de outro, à proposta comunicativa pretendida com o telespectador, pois disto depende a visão de mundo construída e, consequentemente, o tipo de produção de linguagem projetada.

\subsubsection{Contexto de atuação}

A emissora, fundada há 60 anos, está inserida em um conglomerado organizacional que hoje é parte integrante e representativa da televisão brasileira, com 122 emissoras (5 reprodutoras ${ }^{1}$ e 117 afiliadas), que cobrem cerca de $98,53 \%$ do território nacional.

No ramo do entretenimento, a produção dramatúrgica responde por, pelo menos, seis produtos na grade: a reprise de uma telenovela, dentro do programa Vale a pena ver de novo, a chamada soap opera das $17 \mathrm{~h}$, as telenovelas das $18 \mathrm{~h}$ (no caso, Joia Rara), das $19 \mathrm{~h}$ e das $21 \mathrm{~h}$ e, regularmente, um seriado ou uma minissérie exibida por volta das 23h. Para sustentar essa produção, a emissora mantém uma central de criação e produção, mais conhecida como Projeto Jacarepaguá ${ }^{2}$ (Projac), localizado no Rio de Janeiro, que, em área total de 1,65 milhão de metros quadrados, abriga espaços dedicados a cidades cenográficas, unidades portáteis para gravação das cenas, estúdios acusticamente tratados, módulos de produção, ilhas de edição de vídeo e de áudio, estações de computação gráfica e estações de produção para Internet, prédio de produção de efeitos especiais (tiros, explosões, maquetes), pós-produção, prédio de arquivo de fitas automatizado e robotizado, efeitos especiais e gráficos, fábricas

Emissoras sediadas em Rio de Janeiro, São Paulo, Brasília, Belo Horizonte e Recife.

2 Dados obtidos em: <www.g1.com.br> 
de cenários e figurinos, além de um extraordinário elenco fixo, sempre à disposição da emissora.

Todo lançamento de uma telenovela representa um significativo valor nela investido, uma nova proposta de trama ao telespectador, uma mobilização por parte da emissora para conseguir manter, pelo menos, aquele índice de audiência previsto para o horário.

E como fazer isso? A inovação nas tramas não é tarefa fácil, sobretudo em se tratando da telenovela das $18 \mathrm{~h}$ que sempre tem, como pano de fundo, a tradicional história de amor, recheada de intrigas e de vinganças. Nos seus 40 anos de existência, as produções das $18 \mathrm{~h}$ têm-se caracterizado por adaptações da literatura brasileira, além de narrativas originais e remakes, marcando-se particularmente pela exploração de tramas de época, que apostam na esmerada reconstituição de um determinado período da história, cuidadosamente recriado.

\subsubsection{Proposta comunicativa}

\section{a) trama de Joia Rara ${ }^{3}$}

A telenovela Joia Rara, exibida de 16 de setembro de 2013 a 4 de abril de 2014, em 173 capítulos, obedeceu ao esquema de recuperação de época, pois se desenvolveu em um tempo e em um lugar muito específico: a cidade do Rio de Janeiro logo após a segunda Guerra Mundial (1934-1945), com seus antagonismos sociais, políticos, religiosos, culturais, associada aos preceitos de tradição budista, que dão um toque peculiar à trama e pretendem ser, no entendimento da emissora, o atrativo maior de interpelação do telespectador para o consumo da telenovela.

Assim, na construção da história de amor entre Franz Hauser (Bruno Gagliasso) e Amélia (Bianca Bin), e a filha do casal Pérola (Mel Maia), suposta reencarnação do lama budista Ananda Rinpoche (Nelson Xavier), que dá a base para a narrativa, convivem as oposições da época: elite rica e núcleo operário;

3 Escrita por Duca Rachid e Thelma Guedes e dirigida por Amora Mautner (geral) e Ricardo Waddington (de núcleo). 
autoritarismo e submissão; austeridade da família tradicional e descontração da vida boemia. A essas tensões ainda se agrega a oposição entre espiritualidade e materialidade, decorrente do núcleo budista inserido na trama.

Por ser uma narrativa de época, passada há mais de 70 anos, a emissora ainda enfrentou o desafio de não poder incluir ações publicitárias, sob a forma de merchandisings comerciais, que pudessem sustentar a produção e assegurar retornos financeiros mais imediatos.

Nesse sentido, e por se tratar de narrativa mística e politizada, foi expressivo o investimento da emissora com o projeto, haja vista a aposta em um núcleo vinculado ao budismo, que constitui, por si só, uma escolha ousada e inovadora, seja pelo caráter inaugural de inserção dentro da telenovela, seja pela escolha estratégica da temática. Afinal, com esse tema, a telenovela está-se propondo, além dos telespectadores habituais da faixa horária, a interpelar todo um público voltado à dimensão espiritualizada, às questões místicas, tão em voga na sociedade contemporânea, levando em conta os ensinamentos práticos e as eventuais mudanças de atitude no corpo e na mente das pessoas, trazidos pelo budismo.

\section{b) recursos de cenário e filmografia}

De maneira geral, a captação de imagens, tomadas, movimentos de câmera e fotografia, para explorar a suntuosidade da região do Himalaia, acrescida do predomínio de tons vermelhos imprimiu à telenovela, no seu início, o caráter cinematográfico, e esse mesmo efeito de sentido foi reproduzido nas cidades cenográficas.

Na reconstituição da cidade do Rio de Janeiro misturam-se imagens e cenas em preto e branco, extraídas de arquivo que reproduzem a vida da época, com cenários das cidades, primeiro mostradas em preto e branco e depois revestidas de cores, para dar mais efeito de realidade ao ambiente recuperado.

Para as locações externas, foram feitas gravações na região nepalesa, com a criação de sets cenográficos na praça principal de Pathan, que aliaram a grandiosidade dos templos orientais e a caracterização budista trazida pelos 
figurantes, ao lado dos principais atores da trama; e nas montanhas do Valle Nevado, no Chile, para a locação da suposta escalada ao monte Everest.

Outro ingrediente de destaque foi a ambientação histórica na cidade do Rio de Janeiro, no período que sucede a segunda Guerra Mundial. A reconstituição da época, manifestada nos cenários, nos elementos decorativos, nos figurinos, nos penteados e maquiagem revela o extremo cuidado, bem como os altos investimentos destinados.

Na construção do núcleo do Cabaré Pacheco Leão, a inspiração foi o tradicional Moulin Rouge, de Paris. Ambientado no bairro boêmio da Lapa e comandado por Arlindo (Marcos Caruso), o cabaré é o palco ideal de combinação entre música e sensualidade, de disputa entre as coristas e de expressão de sonhos impossíveis e amores mal-resolvidos.

Para a ambientação do núcleo do cortiço, de uma massa proletária ansiosa por uma vida melhor e, por isso, simpática ao movimento socialista, a emissora criou um espaço cenográfico, também ambientado na Lapa, de pessoas mais humildes, a maioria operários da fundição, que é comandada com mãos de ferro pelo empresário Ernest Hauser (José de Abreu).

\section{c) trilha sonora exclusiva e abertura artesanal}

A trilha sonora ${ }^{4}$, composta especialmente para a novela, foi uma criação de cantor e compositor Gilberto Gil. Em termos de abertura, a telenovela buscou uma linguagem muito própria e diferente: os personagens principais Pérola, Ananda Rinpoche, Franz Hauser e Amélia foram representados, de forma lírica,

4 Ontem veio a chuva / Hoje veio o vento / A qualquer momento / O fogo virá / Coração vadio / Tem que estar atento / Pois cada elemento / Terá seu lugar / Água e ar e fogo / Terra pedregosa / Pedra preciosa / Tudo a merecer / Um canto na alma / Um tapa na cara / Uma joia rara / Um tanto sofrer / Uma joia rara / Um tanto sofrer / No meio do rio / A voz do barqueiro / Lança o desafio / Buda há de escutar / No meio da noite / No meio do frio / Ao fisgar do açoite / Buda há de encontrar / Justo, justo meigo / Entre o belo e o feio / Longe do receio / Perto do Sonhar / Onde o amor se esconde / Onde o amor se ampara / Uma joia rara / Um certo penar / Uma joia rara / Um certo penar. 
por desenhos artesanais ${ }^{5}$, sem efeitos de animação, que recontavam os principais momentos da trama.

Ao lado dos altos investimentos realizados, a Globo também propôs mudanças na sua grade, da ordem de reiterações da nova produção para, fundamentalmente, garantir a fidelização do público telespectador e, consequentemente, o sucesso de Joia Rara.

\subsection{Dimensão intertextual}

Além do lançamento da trama, a emissora, usando seus recursos técnicos de produção, circulação e consumo, também propôs alterações em seus programas, a fim de que a telenovela ganhasse destaque e pudesse, de forma mais efetiva, interpelar o telespectador e mantê-lo fiel à novidade. Essas replicações apareceram sob diferentes tipos de texto, que basicamente funcionaram como produções autopromocionais.

\section{a) segunda tela}

Segunda tela é um tipo de texto autopromocional que consiste na sobreposição informativa com divisão da tela, normalmente veiculada na última semana de exibição de uma telenovela. Assim, enquanto na tela maior são relacionados os créditos e a equipe de apoio da telenovela que está em fase de finalização; no rodapé, como uma janela, aparece o nome da nova telenovela a ser iniciada e a data de seu lançamento. Esse desdobramento da tela aconteceu na última semana de exibição da telenovela Flor do Caribe, quando a audiência era mais alta, já convocando o telespectador para a estreia de Joia Rara, a ter lugar naquele mesmo horário, na semana seguinte.

\section{b) chamada intervalar}

Chamada intervalar é um tipo de texto autopromocional que exibe cenas gravadas da nova trama, com vistas a interpelar o telespectador e a despertar sua curiosidade e interesse. Normalmente aparecem em referências diárias, nos

5 Produção da ilustradora Luciana Grether Carvalho. 
intervalos entre programas e/ou entre blocos de um mesmo programa, sobre aquele novo produto da emissora, com a finalidade de antecipar os acontecimentos que ocorrerão naquele dia, instigando o telespectador para seu consumo, haja vista os desdobramentos mostrados. Essa prática ocorreu insistentemente durante a primeira semana de exibição de Joia Rara, em diferentes horários da programação, quando o público ainda não havia assimilado a nova proposta temática e precisava habituar-se ao conteúdo da trama.

\section{c) quadro dentro de programas}

Quadro é um tipo de texto autopromocional que consiste na inserção de atores, diretores, autores, realizadores, em outros programas de grade, para contar peculiaridades da nova trama, antecipar cenas já gravadas, com vistas à familiarização do telespectador com a nova atração e à conquista de sua fidelização. A semana do pré-lançamento de Joia Rara foi recheada de inserções ou quadros nos seguintes programas da RGT:

Vídeo show ${ }^{6}$ - programa diário, de segunda a sexta, às $13 \mathrm{~h} 50 \mathrm{~min}$, sobre bastidores da emissora, preparação dos atores, lançamento de programas, além de entrevistas e brincadeiras com os famosos - exibiu, na semana, quatro matérias sobre a novela: em 12/09/2013, o ator Carmo Dalla Vecchia, com uma máquina fotográfica, fez registros da região do Nepal e falou de sua experiência como fotógrafo e das emoções vivenciadas naquela localidade; em 13/09/2013, uma síntese do programa Globo Repórter (também exibido na mesma semana), liderado pela equipe da jornalista Gloria Maria, fez referências ao Nepal e às gravações da novela Joia Rara; em 16/09/2013, a atriz Carolina Dieckmann, no Projac, falou sobre a personagem na trama e sobre a coincidência de seu aniversário ocorrer justamente no dia da estreia; ainda em 16/09/2013, uma matéria feita especialmente para o Vídeo show, mostrou cenas gravadas no Nepal e depoimentos da diretora, Amora Mautner, e dos atores Caio Blat, Bianca

6 Programa há 30 anos no ar, com direção, no período de análise, do núcleo de Ricardo Waddington. 
Bin e Bruno Gagliasso, sobre a magia daquela localidade que dá o pano de fundo da trama.

Encontro com Fátima Bernardes ${ }^{7}$ - programa diário, de segunda a sexta, às 10h40min, sob o comando da jornalista Fátima Bernardes, que mistura informação, matérias de comportamento, prestação de serviço, humor, música e interatividade com o público, em tom informal - trouxe, em 11/09/2013, o ator Domingos Montagner para falar de seu personagem Raimundo, líder socialista com forte influência no núcleo do cortiço; em 16/09/2013, os atores Nelson Xavier e Marcos Caruso falaram dos personagens e da trama como um todo. No mesmo dia, ainda, a apresentadora exibiu cenas, filmadas no Nepal, com alguns atores e figurantes da trama.

Domingão do Faustão ${ }^{8}$ - programa semanal, do final das tardes de domingo, sob o comando de Fausto Silva, que mistura informação, música, atrações diversas para um auditório numeroso, - apresentou, em 15/09/2013, uma entrevista com o diretor Ricardo Waddington, que falou sobre a trama, os principais atores, a locação no Nepal. Além disso, o apresentador fez referências aos atores Nelson Xavier e Marcos Caruso que, no dia seguinte, estariam no programa da Fátima, em clara remissão intertextual.

Os quadros, acima de tudo, exibidos em horários predeterminados e para públicos específicos, trouxeram outros olhares sobre a trama, anunciaram acontecimentos e buscaram atrair o público telespectador.

\section{d) emissão de programa especial}

Duas emissões de programa foram realizadas inteiramente sobre o tema de Joia Rara, na semana anterior ao lançamento: Globo Repórter e Esquenta!.

Globo Repórter ${ }^{9}$ - toda a emissão de 13/09 centrou-se na exibição da região do Nepal, mostrada inicialmente por imagens panorâmicas, enriquecidas

7 Programa lançado em 2012, com direção de J. B. Oliveira (Boninho) e Mário Marcio Bandarra.

8 Programa lançado em 1989, com direção de Jayme Praça e produção executiva de Alexandre Ishikawa.

9 Programa lançado em 1973, pertencente ao setor de telejornalismo. 
pela grandeza das montanhas da Cordilheira do Himalaia à sua volta, e pelas imagens externas das cidades de Pathan (a mais budista delas), Kathmandu e Bhaktapur, com especial destaque para a praça central. Todo esse cenário descortinou um país mágico e distante, que abriga um povo misterioso (hinduístas e budistas), preocupado com o caminho do equilíbrio entre o corpo e a mente, e que hoje é motivo de disputa entre dois grandes países asiáticos: a Índia e a China. Toda a emissão centrou-se na exuberância e mistério daquela região, convocando o telespectador para conhecer o país onde viveu Buda, o príncipe iluminado, e palco para a próxima telenovela das $18 \mathrm{~h}$. Em toda a emissão, houve referência direta à equipe de produção da telenovela, aos profissionais que trabalhavam nos bastidores, à parafernália de recursos utilizados nas locações, ao set cenográfico montado na praça principal, com os figurantes monges em sua encenação, embaralhando assim o cenário real, que emoldurava as gravações, com os diversificados e valiosos recursos disponibilizados para a preparação das gravações da trama ficcional. A emissão também reforçou a fusão entre ator social e personagem ficcional: Caio Blat, vestido como o personagem ficcional Lama Sonan, depôs, como ator social, sobre seu papel na narrativa. O mesmo aconteceu com os personagens Pérola e Franz Hauser, que misturaram ficção e realidade; ou da diretora Amora Mautner, que falou sobre as pessoas locais e a prática do budismo: a ciência da mente. Nas cenas mostradas, os planos da ficção e a realidade apareceram completamente embaralhados.

Esquenta! ${ }^{10}$ - A emissão do dia 15/09 dedicou-se ao tema do budismo, evidenciado na simulação de ambiente que mostrou, de início, um templo de meditação, em que todos, inclusive a plateia, entoava um mantra "om mani padme hum", em um cenário de pouca luz e de suposto relaxamento. Todos os convidados, começando pela apresentadora, trajavam roupas características do movimento budista, com forte predomínio dos tons amarelados, alaranjados e vermelhos, e música alusiva à comemoração. Além disso, a emissão do programa contou com a participação de professores, consultores, monges e

10 Programa com direção de Mônica Almeida e Daniela Gleiser, gerência de produção de Alexandre Scalamandré e criação de Hermano Vianna e Regina Casé. 
especialistas, que prestaram esclarecimentos sobre a tradição budista, o sentido do mantra, seus maiores ensinamentos: compaixão e sabedoria, e sua busca pela iluminação; ainda trouxe entrevista com alguns atores da trama, como Caio Blat, Bianca Bin e Mel Maia, que comentaram sobre a vivência no Nepal, o convívio com os monges e a participação na novela, sempre de forma descontraída, alegre e contagiante; trouxe o criador da trilha sonora, o cantor e compositor Gilberto Gil, que conversou com a apresentadora sobre a música, sua trajetória pessoal e musical, ao lado de duas filhas Preta e Bela Gil, que falaram sobre o pai e seus projetos pessoais.

De maneira geral, as duas emissões permitiram alguns comentários, relativos aos efeitos de sentido propostos.

Em relação ao Globo repórter, programa jornalístico de caráter documental, houve adequação entre o conteúdo explorado e a emissão, direcionada à fascinante e exuberante região do Nepal, que é conhecida pela espiritualidade característica do povo, pelo culto às tradições milenares, pela peculiaridade de alguns de seus hábitos de vida. Com esse caráter, as referências tanto à viagem de nove dias pela trilha que leva ao templo Tengboché, o mais alto da região, como a visita à casa de um morador local para conhecer os hábitos em família não causaram estranhamento. O diferencial, na emissão, foram as entrevistas com alguns atores e com a diretora da telenovela, além da apresentação de cenas lá rodadas e dos bastidores dessas gravações, para enfatizar ao telespectador as peculiaridades daquela região e as dificuldades encontradas na ambientação da trama.

Quanto ao Esquenta!, há que se ressaltar que, apesar de todas as estratégias adotadas para tratar o tema do budismo, como os ensinamentos trazidos, as encenações representadas, o cuidadoso cenário representativo dessa cultura milenar, nem sempre o programa conseguiu com eficácia articular todos os participantes. Não se pode esquecer que Esquenta! é um programa voltado ao samba de raiz, aos hábitos da periferia, e, por isso, em alguns momentos, os músicos convidados, Emicida, Rael e Jeito Mole e o humorista Marcelo Adnet pareceram deslocados. Por mais que a produção tenha criado um 
cenário impecável e tentado promover inter-relações entre os convidados, nem a descontração característica da apresentadora foi capaz de integrar todos os participantes dos quadros em torno daquele tema, que pareceu relativamente artificial dentro do contexto do programa.

\section{Considerações finais}

A reflexão aqui desenvolvida buscou inicialmente, ainda que de forma breve, esboçar os princípios que sustentam a proposta de estudo no âmbito da semiótica discursiva, assim como a construção teórico-metodológica dela decorrente, para, então, reconhecer procedimentos e estratégias empregadas pela emissora, e concretizadas em produções autopromocionais, por ocasião de um novo lançamento em sua grade.

O fato de ser dona do próprio negócio permite à Rede Globo criar o palco privilegiado para a autopromoção. Qualquer lançamento, iniciativa ou projeto, aliado ao grau de experimentação, de ousadia e de novidade, próprio da emissora, encontra nela mesma o espaço adequado a sua projeção, confirmando o entendimento de que nada se passa na televisão sem que algum

benefício seja revertido para a emissora. É natural, portanto, o que aliás tem sido prática comum em lançamentos dramatúrgicos, o empenho e a mobilização da emissora com o novo programa.

Assim, para garantir o sucesso do empreendimento, a ação autopromocional, resultado de cuidadoso planejamento, (1) exige vultosos investimentos, o que envolve escolha de cenário surpreendente, temática até certo ponto inaugural, inovações tecnológicas, adoção de recursos especiais de filmografia, definição de uma abertura diferente para marcar o tema escolhido; (2) necessita de adequada interação com o público, o que implica a construção de uma trama que atraia o interesse e que conquiste a simpatia do público; e (3) mobiliza a grade da emissora, o que acarreta divulgação contínua do lançamento, reiterados chamamentos intervalares e discussão da nova temática em programas da emissora, seja em quadros, seja em programas especiais. 
Todas essas estratégias, presentes de forma sutil ou explícita, estão a serviço da emissora para surpreender o telespectador, garantir a manutenção dos altos índices de audiência, atrair o anunciante para seus espaços e consolidar a posição da rede no cenário nacional.

\section{Referências}

BAKHTIN, Mikhail. Marxismo e filosofia da linguagem. São Paulo: Hucitec, 1981.

BAKHTIN, Mikhail. Estética da criação verbal. 2. ed. São Paulo: Martins Fontes, 1997.

CASTRO, Maria Lília Dias de. A fala autorreferencial na televisão brasileira: estratégias e formatos. Revista Internacional de Comunicación Audiovisual Publicidad y Literatura, Sevilha, v. 1, n. 10, p. 7893, 2012. Disponível em: <http://www.revistacomunicacion.org>. Acesso em: 06 jun. 2012.

CASTRO, Maria Lília Dias de. Promocional: um processo convergente entre mundos, mídias e plataformas. In: DUARTE, Elisabeth; CASTRO, Maria Lília Dias de. Convergências midiáticas: produção ficcional - RBS TV. Porto Alegre: Sulina, 2010. p. 35-44.

CASTRO, Maria Lília Dias de. Em torno de uma gramática promocional em televisão. In: SILVEIRA, Alda Cristina Machado (Org.). Estratégias midiáticas. Santa Maria: FACOS-UFSM, 2012. p. 115-128.

DUARTE, Elizabeth B. Televisão: ensaios metodológicos. Porto Alegre: Sulina, 2004. Col. Estudos sobre o audiovisual.

DUARTE, Elizabeth. Bastos; CASTRO, Maria Lília Dias de. Produção midiática: o ir e vir entre teoria, metodologia e análise. In: BARICHELLO, Eugênia Mariano da Rocha; RUBLESCKI, Anelise (Orgs.). Pesquisa em comunicação: olhares e abordagens. Santa Maria: Facos-UFSM, 2014. p. 67-87.

ECO, Umberto. Tevê: a transparência perdida. In: Viagem na irrealidade cotidiana. Rio de Janeiro: Nova Fronteira, 1984.

FABBRI, Paolo. El giro semiótico. Barcelona: Gedisa, 1999.

GREIMAS, Algirdas Julien. Prefácio: as aquisições e os projectos. In: COURTÉS, Joseph. Introdução à semiótica narrativa e discursiva. Coimbra: Almedina, 1979.

GUEDES, Thelma; RACHID, Duca. Joia Rara. Telenovela. Rede Globo de Televisão. 1913-1914. <http://gshow.globo.com/novelas/joia-rara/extras/noticia/2013/09/do-brasil-ao-nepal-confira-ascuriosidades-das-gravacoes-na-regiao-do-himalaia.html>

JOST, François. Compreender a televisão. Porto Alegre: Sulina, 2010.

MACHADO, Arlindo. A televisão levada a sério. 3. ed. São Paulo: Senac, 2003.

PÉNINOU, Georges. Intelligence de la publicité: étude sémiotique. Paris: Robert Laffont. 1972.

WOLTON, Dominique. Elogio do grande público: uma teoria crítica da televisão. Tradução de José Rubens Siqueira. São Paulo: Ática, 2006.

\section{Maria Lília Dias de Castro}

Professora do Programa de Pós-Graduação em Comunicação da Universidade Federal de Santa Maria (UFSM); pós-doutora em Comunicação pela Université de Paris III - Sorbonne Nouvelle; coordenadora da pesquisa Comunicação Televisual - COMTV, integrante dos Grupos de Pesquisa CNPq (versão 20/11/09); coordenadora da pesquisa $A$ utilização estratégica da função promocional na televisão comercial brasileira.

E-mail: mlilia@terra.com.br

Currículo: http://lattes.cnpq.br/8927752518456308 